\title{
Medievalista
}

Online

$29 \mid 2021$

Número 29

Tese de Dutoramento em Estudos Medievais, apresentada à

Universidade de Santiago de Compostela, 2019. Orientação das

Professoras Doutoras Yara Frateschi Vieira e Maria Isabel Morán Cabanas

\section{Espetáculo para o céu: a construção do jogral}

\section{Janaína Marques}

URL: https://journals.openedition.org/medievalista/3962

DOI: 10.4000/medievalista.3962

ISSN: $1646-740 \mathrm{X}$

\section{Editora}

Instituto de Estudos Medievais - FCSH-UNL

\section{Edição impressa}

Paginação: 353-362

\section{Refêrencia eletrónica}

Janaína Marques, «Espetáculo para o céu: a construção do jogral», Medievalista [Online], 29 | 2021, posto online no dia 01 janeiro 2021, consultado o 12 junho 2021. URL: http://journals.openedition.org/ medievalista/3962 ; DOI: https://doi.org/10.4000/medievalista.3962

Este documento foi criado de forma automática no dia 12 junho 2021.

\section{(c) (7) (8)}

Mediavalista está licenciado com uma Licença Creative Commons - Atribuição-NãoComercial 4.0 Internacional. 


\title{
Espetáculo para o céu: a construção do jogral
}

\author{
Janaína Marques
}

\section{NOTA DO EDITOR}

Data recepção do artigo / Received for publication: 15 de Maio de 2020

1 Nos séculos XII e XIII, os jograis encontravam-se no ápice da sua influência. Graças à sua atuação itinerante pelas diversas regiões da Europa Ocidental e à pluralidade dos seus meios de expressão, conseguiam nessa época atingir um público vasto e variado. 0 amplo leque das habilidades jogralescas por um lado enriquece a atuação e permite cativar os espectadores; por outro, porém, essa mesma multiplicidade acaba por criar imprecisão no vocabulário utilizado para designar a arte e o artista: a categoria abrangia do compositor ao malabarista, passando pelo cantor, o acrobata, o instrumentista e o domador de animais, sem distinguir os bons dos maus, os talentosos dos oportunistas. Desencadeia-se, por isso, uma insatisfação e a condenação por parte de clérigos, de trovadores e dos próprios jograis. Apesar disso, esses artistas conquistaram o reconhecimento social, transformando-se em um canal de comunicação inigualável, com uma estética interativa e eficiente, fundamental para a própria estrutura e sobrevivência da sociedade cortesã medieval.

2 Vigorava, então, um discurso religioso condenatório contra esses artistas, seja em relação às suas atuações específicas, seja em relação ao público que os acolhia e recompensava. Tal postura, entretanto, encontrou forte oposição em São Bernardo de Claraval, tanto em seus livros como em seu trabalho evangelizador, oferecendo um contraponto à hegemonia teológica ${ }^{1}$. Para reforçar a nova concepção, surge São 
Francisco de Assis que, com sua mística e seu estilo, abre definitivamente a porta da igreja para os artistas, fazendo-se ele mesmo jogral de Deus².

3 Nesse período, as narrativas miraculosas começam a estampar um protagonista inclassificável, que poderíamos denominar "jogral devoto": ele transita livremente entre o profano e o sagrado, tem a ousadia de realizar a sua arte dentro da igreja, junto ao altar, aos pés da Virgem, e ainda ser o destinatário de milagres portentosos. Assim, a tese busca compreender o que distingue a sua atuação das demais, perseguindo os motivos que teriam levado à criação dessa personagem, bem como sua coerência com a arquitetura da trama. Para tanto, avaliamos os embates teológicos que se desenvolviam no seio da igreja, como as novas concepções teriam possibilitado a reabilitação desse artista e também dimensionar o conflito com a hierarquia eclesiástica e as interações com a plateia. Em relação aos milagres, será necessário abordá-los nas suas múltiplas funções didáticas, incluindo a sua possível influência na execução do espetáculo. Sob esse ângulo, procuramos identificar os elementos do discurso religioso que construíram esse jogral, bem como compreender a especificidade de sua performance, que se realiza na confluência da dimensão sagrada e artística.

4 Com este objetivo, definimos, o seguinte corpus: as Cantigas de Santa Maria 8, 194, 238, 259 e 2933; as versões latinas e francesas das CSM 8 e $259^{4}$; e as narrativas que estabelecem um diálogo com as cantigas acima referidas: Volto Santo di Lucca ${ }^{5}$, nas versões latina e francesa; O jogral de Notre Dame ${ }^{6}$; O Romance de Blaquerna ${ }^{7}$; e São Pedro e o jogral ${ }^{8}$. Consideramos também eventuais relações com outras obras contemporâneas, tais como Daurel e Beton ${ }^{9}$, Roman de Flamenca ${ }^{10}$, Le jongleur d'Ely et le Roi d'Angleterre ${ }^{11} \mathrm{e}$ Abril Issia ${ }^{12}$.

Optamos por extrair do repertório mariano afonsino apenas aquelas cantigas que nomeiam explicitamente o protagonista como jogral, mesmo considerando que em outras obras a personagem central poderia ser associada ao artista, como, por exemplo, o escolar de Salamanca da CSM 291 e o óme boo da CSM 307. Temos ainda a CSM 172, que menciona o termo apenas no último verso da derradeira estrofe como forma da conclusio, fazendo referência à performance futura ${ }^{13}$. Para a seleção das demais narrativas, procuramos detectar um vínculo com as cantigas, priorizando dois aspectos: o contexto religioso e o tipo de habilidade envolvida na apresentação.

6 A relação do jogral com o sagrado, convém ressaltar, está representada ainda em outras obras que não serão objeto de nossa análise, entre as quais podemos citar: Vida de Santo Domingo de Silos, de Gonzalo de Berceo ${ }^{14}$; a narrativa anônima De l'hermite qui se desespera por ce qu'il devoit avoir le jougleour a compagnon ${ }^{15}$; Llibre de Contemplació de Ramon Llull ${ }^{16} \mathrm{e}$ alguns dits e fabliaux ${ }^{17}$. A nossa investigação, portanto, concentra-se no jogral enquanto personagem, fruto da teologia emergente, e não como figura da realidade sociocultural, apesar de encontrarmos registros de sua atuação em igrejas e festividades litúrgicas.

7 Como não temos documentos da época dedicados à descrição da performance, restam ao pesquisador as fontes disponíveis, da literatura à iconografia. Portanto, para compreender essas narrativas, articulamos sistematicamente a interpretação do texto à interpretação da iluminura, que sempre traz um segundo nível de leitura, como salienta Chico Picaza ${ }^{18}$. Em alguns casos, buscamos esculturas e pinturas de interior de igreja, mas as grandes fontes serão as miniaturas e os marginalia dos manuscritos de carácter devocional e literário.

8 Na primeira etapa da investigação, analisamos como o jogral era considerado no discurso religioso até então dominante, observando os argumentos condenatórios, que 
vinculam a sua gestualidade desregrada aos vícios - como a hipocrisia, a lascívia, a vaidade e o engano. Conforme o mapeiam as investigadoras Carla Casagrande e Silvana Vecchio, a condenação a esses artistas emerge, sobretudo, de manuais de predicação, de direito canônico e em livros dirigidos aos laicos, ensinando condutas segundo o modelo cristão ${ }^{19}$. Nestas obras, a censura ao jogral ocorre de duas maneiras: diretamente, acusando-o de disseminar o pecado; e indiretamente, acusando o público que o acolhe e o sustenta. A recomendação era clara: esses artistas deveriam abandonar o seu ofício, exceto aqueles que se dedicavam a cantar a vida dos santos e dos reis. Essa concepção pode ser encontrada, por exemplo, na Summa Confessorum do bispo Thomas de Cobham, no Livro de Confissões do clérigo Martin Perez e na obra de Pierre le Chantre e John de Salisbury.

9 Outras ideias, no entanto, foram se infiltrando no discurso religioso hegemônico, renovando as concepções teológicas e pastorais e encaminhando-o lentamente para uma reabilitação do artista. Os mesmos pontos que foram utilizados para condená-lo como a teatralidade e o estilo de vida itinerante -, servirão não apenas para a sua redenção, mas para situá-lo como referência teológica e pastoral, como revelam as obras e as atuações de São Bernardo de Claraval e São Francisco de Assis.

10 São Bernardo começa sua teologia revelando numerosas práticas que corrompiam a vida monástica e a hierarquia eclesiástica e promovendo um retorno às raízes evangélicas. Em uma epístola dirigida ao clérigo Origerio, São Bernardo constrói uma imagem surpreendente, em que compara a atuação do jogral acrobata, que anda com as mãos no chão e os pés no ar, com a atuação do cristão no mundo, que é sempre objeto de zombaria, justamente por desprezar aquilo que o mundo mais valoriza: a riqueza e o poder $^{20}$. Para fundamentar essa abordagem, Bernardo retoma a concepção paulina de que o cristão está em último lugar e é exposto como espetáculo diante dos olhos dos homens ( $1^{\mathrm{a}}$ carta aos Corintios 4,9$)$, e que a loucura de Deus é mais sábia do que a sabedoria dos homens - uma referência que está presente em quase todas as narrativas. É interessante notar que São Bernardo escolhe para construir a sua imagem justamente o jogral dedicado aos gestos, a categoria mais baixa na hierarquia jogralesca, aquele que atua em silêncio e não canta nem toca instrumentos musicais honrados.

11 Curiosamente, esta metáfora de São Bernardo se concretizará na narrativa milagrosa Tumbeor de Nostre Dame. Neste enredo, que se desenvolve justamente no mosteiro de Claraval, o protagonista, realizando uma acrobacia com os pés para cima, declara à Virgem a frase que sintetiza todo o drama: "Eu serei o seu jogral" 21 .

12 Posteriormente, São Francisco recupera a imagem do jogral não apenas para técnicas de predicação, mas fazendo de sua própria vida um espetáculo aos olhos do Senhor. Depois de compor o Cântico das Criaturas, como relata a obra Espelho de perfeição, Francisco pede para que os melhores frades pregadores saiam pelo mundo evangelizando e cantando como "jograis do Senhor"22. Na mesma linha, outro relato conta que Francisco, pregando em praça pública sobre a humildade, interrompe o discurso e pede para o povo aguardá-lo. Então, fica inteiramente nu, pega uma corda, passa o laço em seu próprio pescoço e pede para que o frade o arraste até à praça, exibindo-o diante de uma platéia perplexa e comovida. Assim, não se contentando com a eficácia de sua fala, ele complementou o discurso com uma ação performática, trazendo para o próprio corpo as consequências da palavra, expondo-se ao ridículo para potencializar a mensagem. 
13 Essas novas concepç̃oes colaboraram na expansão vertiginosa do culto à Virgem Maria. De acordo com o relato dos evangelistas, especialmente de Lucas, Maria, depois de gerar o próprio criador do universo, de cuidar e de educar o Deus encarnado, vai apagando-se, escondendo-se, até ressurgir, em silêncio, na cena final, diante do filho crucificado (Lucas 1, 26-56; João 19, 25-27), tornando-se, assim, o exemplo máximo da humildade. Sob esse ângulo, o novo discurso religioso nutre-se nos movimentos de veneração a Maria, colocando-a como corredentora e mediadora universal. É em tal perspectiva que se desenvolve o vínculo entre a Virgem e o jogral, pois ambos ocupam posições periféricas, subalternas, mas possuem, ao mesmo tempo, uma força aglutinadora capaz de veicular mensagens pujantes.

Nas etapas seguintes da investigação apresentamos o jogral devoto nas narrativas, começando por aquelas que se passam dentro do espaço sagrado, igreja ou mosteiro, com o intuito de compreender a sua relação com o divino e investigar, do ponto de vista teológico, o que legitima a sua presença. Assim, o foco se volta para os seguintes textos: o milagre de Rocamador, que conta com a versão latina, presente na coletânea $D e$ Miraculis Sancte Marie de Rupe Amatoris ${ }^{23}$, a versão francesa dos Miracles de Nostre Dame ${ }^{24}$, de Gautier de Coinci, e a versão afonsina, na CSM 8; o Volto Santo di Lucca, nas versões latina e francesa; a CSM 259, que se passa em Arras, em duas versões, latina e francesa em dialeto picardo ${ }^{25}$; a CSM 293, que traz um jogral dedicado aos gestos proveniente de Lombardia; o Tumbeor de Nostre Dame, que apresenta o acrobata; e o Romanç de Evast e Blaquerna, de Ramon Llull, que coloca em cena o jogral domador de animais. Inicialmente, realizamos a contextualização das obras para em seguida explorar os versos e as imagens, nos casos em que contamos com testemunhos pictóricos, e identificamos as particularidades de sua atuação.

Em seguida, nos dedicamos aos milagres que se passam em outros espaços e que apresentam protagonistas substancialmente diferentes daqueles que encontramos no corpus inicial: a CSM 238, que apresenta o jogador de dados, um "tafur" que se recusa à conversão e é condenado ao inferno; o fabliau $D^{\prime}$ un jugleor qui ala en enfer et perdi les ames as dez, também conhecido como Saint Pierre et le Jongleur, em que seguimos a trajetória do jogador que, ao contrário do relato anterior, é salvo do inferno pela intercessão de São Pedro; e a CSM 194, que coloca em cena um intérprete, cantor e instrumentista. Contribuindo para a análise da última cantiga, introduzimos outras narrativas que ampliam a compreensão do jogral e trazem novas chaves de leitura, como o Roman de Flamenca e o cantar de gesta Daurel et Beton.

Realizado esse percurso, identificamos a especificidade do jogral devoto, por meio dos quatro elementos estruturantes de sua performance: a habilidade artística; o ambiente de atuação; a relação com a plateia; e a dinâmica do milagre. Articulando as abordagens dos textos cantados, narrados e corporalizados, extraímos alguns aspectos essenciais dessas tramas, como a intertextualidade bíblica, o humor, que subjaz nas entrelinhas, a versatilidade do protagonista, atestada pelas iluminuras, a naturalidade com que ele se apropria dos espaços sagrados e o triângulo performático, composto por plateia, jogral e divindade. No contexto de uma profunda reforma teológica, essa personagem, inserida no movimento catequético, esmera-se em seu espetáculo, a ponto de evangelizar a própria Igreja.

17 Ao investigar a atuação da autoridade eclesiástica nestas narrativas, deve ser assinalada a presença de monge ou bispo, que age sempre no sentido de impedir a performance do jogral, mesmo diante da evidência do fato sobrenatural. Na Cantiga de Santa Maria 8, por 
exemplo, texto e iluminura revelam a mudança de atitude do monge, que se prostra aos pés do jogral.

Nesta oposição da hierarquia eclesiástica, detectamos a ressonância do discurso condenatório em relação ao artista. É como se essas narrativas declarassem, inspiradas em São Bernardo, que a devoção sincera do jogral é o exemplo a ser seguido, e a atitude intolerante da Igreja é a realidade a ser superada mediante o pedido de perdão de seus membros.

19 Antes de ser um profissional, o jogral é uma pessoa imersa na cultura medieval, marcada pela religiosidade, mas também pela existência de uma tensão permanente entre as práticas profanas e os cultos católicos. E é justamente essa interseção que constitui o foco das nossas investigações, pois quisemos apreender as especificidades da nova personagem que denominamos "jogral devoto". Nas narrativas analisadas, o humor, como assinala Menéndez Pidal, está presente em todas as tramas enquanto atmosfera resultante do choque entre o religioso e o profano, da surpresa causada pela proximidade da arte jogralesca com o altar do sacrifício.

Ao comparar o cristão ao acrobata, São Bernardo de Claraval abriu as portas para o imaginário popular consolidado nessas narrativas, a começar por suas próprias aventuras. Diante da Virgem ou do Crucificado, diante da própria miséria ou solidão, o jogral devoto realiza a sua arte com o máximo empenho e integra o sagrado no cotidiano. Em seu espetáculo, o artista experimenta um êxtase semelhante aos arroubos místicos do santo de Assis, cujas palavras e performances também inspiraram esse universo. Coerente com tal perspectiva, a Imitatio Christi foi incorporando também a “imitação do jogral”, responsável por desenvolver uma estética singular, ao mesmo tempo sedutora e desconcertante, como procuramos demonstrar ao longo do nosso trabalho.

\section{NOTAS}

1. BERNARDO DE CLARAVAL - Obras Completas de San Bernardo. Madrid: Biblioteca de Autores Cristianos, 2003.

2. FRANCISCO DE ASSIS - "Speculum perfectionis, seu Sancti Francisci Assisiensis Legenda Antiquissima “. in SABATIER, Paul (ed.) - Collection de documents pour l'histoire religieuse et littéraire du Moyen âge. Tome I. Paris: Fischbacher, 1898.

3. METTMANN, Walter - Cantigas de Santa María, vol. I, II, III. Madrid: Castalia, 1986-1989.

4. A partir de agora passaremos a nos referir às Cantigas de Santa Maria como CSM, sigla seguida do número da cantiga correspondente.

5. Cfr. FOERSTER, W. - "Le Saint Vou de Luques". Romanische Forschungen 23 (1907), pp. 1-55; BERTOLUCCI PIZZORUSSO, Valeria - La Vergine e il Volto. Il Miracolo del Giullare. Lucca: Pacini Fazzi Editore, 2009, pp. 18-46.

6. BRETEL, Paul - Le jongleur de Notre-Dame. Paris: Honoré Champion, 2003. 
7. LLULL, Ramon - Romanç d'Evast e Blaquerna. Ed. A. SOLER e J. SANTANACH. Barcelona: Barcino, 2016.

8. NOOMEN, Willem - Le jongleur par lui-même. Choix de dits et de fabliaux. Paris : Louvain, 2003.

9. MEYER, Paul - Daurel et Beton chanson de geste provençale. Paris: Firmin Didot, 1880.

10. MANCINI, Mario - Flamenca. Roma: Carocci, 2006. Guiar-nos-emos ainda pela tradução ao castelhano ROSSELL, Antoni - Flamenca: novela occitana del siglo XIII. Andorra: Anem Editors, 2019.

11. NOOMEN, Willem - Le jongleur par lui-même ....

12. FIELD, Hugh - Obra poética Raimon Vidal de Besalú. I. Barcelona: Curial,1989.

13. Cfr. FIDALGO FRANCISCO, Elvira - "Joculatores qui cantant gesta principum et vitas sanctorum: as cantigas de Santa Maria, entre a lírica e a épica”. in COUCEIRO, Xóse Luis; et al. (Coord.) - Homenaxe ó profesor Camilo Flores. Tomo II. Santiago de Compostela: Universidade de Santiago de Compostela, 1999, pp. 318-334. Para o conceito de "performance futura", veja-se DISALVO, Santiago Anibal; PABLO ROSSI, Germán - "Entre la juglaría y la liturgia: dos modos de performance en las Cantigas de Santa María de Alfonso X". in PLESH, Melanie (ed.) - Analizar, interpretar, hacer música de las Cantigas de Santa María a la organología. Buenos Aires: Gourmet, 2013, pp. 209-232.

14. GONZALO DE BERCEO - Vida de Santo Domingo de Silos. Alicante: Biblioteca Virtual Miguel de Cervantes, 2005, (baseada na edição de Brian Dutton, London, Tamesis, 1978). [Consultado em 09 de maio de 2020]. Disponível em http://www.cervantesvirtual.com.

15. ALLEN, Louis - De l'Hermite et del Jougleour. A Thirteenth Century 'Conte Pieux'. Chicago: Joseph Solsona, 1925.

16. LLULL, Ramon - Libre de Contemplació. Barcelona: Barcino, 2005.

17. NOOMEN, Willem; BOOGAARD, Nico H. J. van den - Nouveau recueil complet des Fabliaux (NRCF). Pays Bas: Assen, 1983.

18. Cfr. CHICO PICAZ, Maria Victoria. - "La teoría medieval de la música y la miniatura de las Cantigas". Anales de Historia del Arte 13 (2003), pp. 83-95.

19. Cfr. CASAGRANDE, Carla; VECCHIO, Silvana - "L'interdizione del giullare nel vocabolario clericale del XII e del XIII secolo". in Il Contributo dei giullare alla drammaturgia italiana delle origini: Atti del II convegno di studio, Viterbo, 17-19 giugno 1977. Viterbo: Amministrazione Provinciale, 1978, pp. 207-258. Das mesmas autoras veja-se ainda "Clercs et jongleurs dans la société médiévale (XII et XIII siècles)". Annales. Économies, Sociétés, Civilisations 5 (Sep-Oct 1979), pp. 913-928.

20. BERNARDO DE CLARAVAL - Obras completas. Vol. VII....

21. BRETEL, Paul - Le jongleur de Notre-Dame..., pp. 202-209

22. FRANCISCO DE ASSIS - Speculum perfectionis..., pp. 109.

23. ALBE, Edmond - Les Miracles de Notre-Dame de Roc-Amadour au XIIe siècle; texte et traduction d'après les manuscrits de la Bibliothèque Nationale. Paris: Honoré Champion, 1908. [Consultado em 24 de janeiro de 2019] Disponível em https://archive.org/details/ lesmiraclesdenot00albe.

24. KOENIG, V. Frederic - Les Miracles de Nostre Dame, 4. Vols. Genève: Droz, 1961-1970. 
25. Para as versões francesa e latina guiar-nos-emos por esta edição: BERGER, Roger Le Nécrologe de la Confrérie des Jongleurs et des Bourgeois d'Arras. Arras: Commission départementale des monuments historiques du Pas-de-Calais, 1970.

\section{AUTOR}

\section{JANAÍNA MARQUES}

Universidade de Santiago de Compostela, Escola de Doutoramento Internacional Programa de Estudos Medievais. Casa dos Catedráticos, Avenida das Ciencias, 6.15782 Santiago de Compostela, Espanha. janamfr@gmail.com. https://orcid.org/0000-0003-2635-4598 